\title{
DIE BESTUURSBEVOEGDHEID VAN PERSONE WAT AS RAMPVERPLEEGSTERS BY DIE PRETORIASE BURGERLIKE BESKERMING GEREGISTREER IS.
}

\author{
SW BOOYENS EN A PEROLD
}

\section{OPSOMMING}

Die noodsaaklike bestuursrol van die rampverpleegster tydens rampoptrede en direk daarna is verken, nagevors en beskryf. Haar bevoegdheid om die verskillende ramp-bestuurstake effektief te kan verrig vóór. tydens en ná rampe wat buite ' $n$ hospitaal plaasvind, is ook nagegaan. Bestuurstake is geïdentifiseer waarmee verpleegsters tydens rampsituasies buite hospitale vertroud behoort te wees. Die navorsingsprojek het deur middel van vraelyste biografiese dato ingesamel met betrekking tot die persone wat as ramp-verpleegsters by Burgerlike Beskerming in Pretoria geregistreer is, met die doel om ' $n$ karsus aan te beveel wat pertinent op hul behoeftes gerig is. Die rampverpleegster se behoefte aan toepaslike verdere opleiding, inoefening of leiding betreffende die geïdenti-fiseerde bestuurstake, is bepaal. Dit het geblyk dat opleiding in die meeste take nodig is, en ' $n$ kursus in rampbestuur vir verpleegkandiges is ontwerp.

\section{SUMMARY}

The essential management role of the disaster nurse during disaster action was outlined, researched and described. Her competency to execute effectively disaster relief tasks before, during and after $a$ disaster occuring outside $a$ hospital, was studied. Management tasks were identified which nurses should have mastered regarding disaster situations occurring outside hospital boundaries. Research data were gathered by means of a questionnaire on the biographic detail of disaster nurses registered with Civil Defence in Pretoria, in order to recommend a course specifically aimed at fulfilling their requirements. The research project identified requirements of the disaster nurse for appropriate further training, practise and guidance regarding the identified management tasks. It became evident that training is required in most of the lasks, and a training course for nurses in disaster management was designed.
Die Wet op Burgerlike Beskerming (Wet no. 67 van 1977 , soos gewysig) maak onder andere voorsiening om persone te werf en op te lei vir moontlike toekomstige rampoptredes. Die vrywilligers word in spanne volgens dissipline ingedeel en die rampverpleegster funksioneer in een van die spanne, naamlik die mediese span. Die rol van die geneesheer en verpleegster skakel ineen. Verpleegsters wat op die ramptoneel hulp verleen, moet voorbereid wees dat daar, onder andere, leierskaps- en bestuurstake van hulle verwag sal word wanneer ' $n$ aantal spanne van die vrywilligerskorps in verskillende dissiplines op die ramptoneel saamwerk. (Eaton 1992:490; Lanros 1983:570).

Gesprekke met verpleegsters wat buite hospitaalverband werk, het op 'n onsekerheid en gevolglike onwilligheid gedui om by rampbeplanning en -verpleging betrokke te raak. Hierdie persone meen dat die nodige opleiding en ervaring van noodbestuursaspekte en noodhulp by hulle ontbreek. Tog beskou die gemeenskap die verpleegster as ' $n$ kundige wat leiding behoort te neem tydens rampsituasies weens haar blootstelling aan bevelsposisies en haar ervaring in die neem van lewensreddende beslissings (Lombard \& Booysen 1986:31).

Die navorsingsprobleem wat sigself dus voorgedoen het, was die volgende:

Beskik persone wat as rampverpleegsters by Burgerlike Beskerming geregistreer is, wel oor die nodige bestuursbevoegdheid om vóor, tydens en ná rampe wat buite 'n hospitaal plaasvind, bestuurstake effektief te kan uitvoer?

\section{DOEL VAN DIE ONDERSOEK}

Die doel van die ondersoek was as volg:

* Identifisering van daardie bestuurstake waarmee verpleegsters tydens rampsituasies buite hospitale vertroud behoort te wees.

* Die bepaling van die rampverpleegster se behoefte aan toepaslike verdere opleiding, inoefening of leiding betreffende die geïdentifiseerde bestuurstake.

* Die insameling van biografiese data met betrekking tot die persone wat as rampverpleegsters by Burgerlike Beskerming in Pretoria geregistreer is, met die doel om ' $n$ kursus aan te beveel wat op hul behoeftes gerig is.

\section{OMSKRYWING VAN BEGRIPPE}

\section{Rampbestuursproses}

Die bestuurskomponente van beplanning, organisering, koördinering, kommunikasie, leierskap, beheer en herstel (stabilisering) is as basiese komponente gebruik soos dit tydens die drie fases van rampbestuur voorkom, naamlik in die voorrampfase, die rampoptredefase en die herstel/stabiliseringsfase.

\section{Rampverpleegster}

Die term rampverpleegster het gedui op persone wat in die dissipline rampverpleging by Burgerlike Beskerming geregistreer is. Hierdie persone het reeds hul basiese verpleegopleiding suksesvol voltooi.

\section{Mediese span}

Die mediese span (ook genoem die gesondheidspan) bestaan uit geneeshere, rampverpleegsters en opgeleide noodhelpers wat as die mediese taakmag tydens rampe deur Burgerlike Beskerming aangewend word vir die versorging van rampslagoffers.

\section{DIE INSTRUMENT}

Die instrument is saamgestel met die doel om die respondente se menings te verkry oor die toepaslikheid van die 38 gelyste rampbestuurstake, sowel as hul persepsies oor die mate van hul eie bevoegdheid met betrekking tot elke taak. Die 38 items of rampbestuurstake is ingedeel in die volgende kategoriee of bestuurskomponente.

\footnotetext{
* beplanningstake

* organiseringstake

* koördineringstake

* kommunikasietake

* leierskapstake

* beheertake

* ná-rampfase-take
} 
In Figuur 1 word hierdie bestuurskomponente soos dit in die rampbestuursproses :oorkom, uiteengesit.

\section{METODOLOGIE}

'n Beskrywende opnamemetode is gevolg. Die teikenpopulasie vir die studie het bestaan uit die 103 persone wat op 1 Mei 1993 by Burgerlike Beskerming in Pretoria in die dissipline rampverpleging geregistreer was. Van hierdie groep persone was 96 vir die ondersoek beskikbaar. Die vraelys waarmee data ingesamel is, het uit drie afdelings/komponente bestaan. Die eerste deel was die een waarmee biografiese data ingewin is; in die tweede deel is rampbestuurstake gelys en die respondente moes deur middel van hul response die toepaslikheid van die take, aldan nie, vir rampbestuur aandui; in die derde gedeelte moes die respondente aandui hoe bevoeg hulle hulself ag om die geïdentifiseerde bestuurstake uit te kan voer.

Die geldigheid van die instrument is bevestig deur kollegas by Burgerlike Beskerming, die Stadsgesondheidshoof, die Direkteur van Burgerlike Beskerming in Pretoria, asook ' $n$ verpleegkundige wie se doktorale tesis gehandel het oor aspekte van hantering van rampslagoffers. Betroubaarheidstoetse soos die Cronbach-Alpha-koëffisiënt-bepaling het op hoë interne konsekwentheid en korrelasie tussen items gedui.

'n Adreslys is van Burgerlike Beskerming in Pretoria bekom en elke rampverpleegster is telefonies genader vir deelname aan die studie. Afsprake is met respondente gemaak vir persoonlike besoeke deur die navorser.

Elke vraelys is deur die respondente self in die teenwoordigheid van die navorser voltooi. Tydens die besoeke, wat ' $n$ gemiddelde tydsduur van 30 minute gehad het, is persoonlike kontak met respondente gemaak. Die navorser het gepoog om dieselfde ingesteldheid teenoor alle respondente te handhaaf en die respondente moes self, sonder hulp, op al die items op die vraelys reageer. Die navorser het die persoonlike hantering van die vraelys en die gepaardgaande besoek nodig geag, omdat die apatie wat so dikwels betreffende Burgerlike Beskerming ondervind word, in hierdie geval tot 'n baie swak terugvoer kon lei, indien vraelyste per pos versend sou word.

\section{BEVINDINGE}

\section{Biografiese besonderhede}

Die meerderheid van die respondente het in die ouderdomsgroep 40 tot 59 jaar geval, was Afrikaanssprekend en het benewens hulle algemene verpleegkunde, ook oor die verloskundige kwalifikasie beskik. Kwalifikasies in verpleegbestuur $(9,4 \%)$, gemeenskapsverpleegkunde $(31,8 \%)$ en sertifikate in bejaardesorg (9\%) was van die bykomende $\mathrm{kwalifikasies} \mathrm{waaroor} \mathrm{hierdie} \mathrm{groep}$ beskik het. 'n Groot persentasie respondente

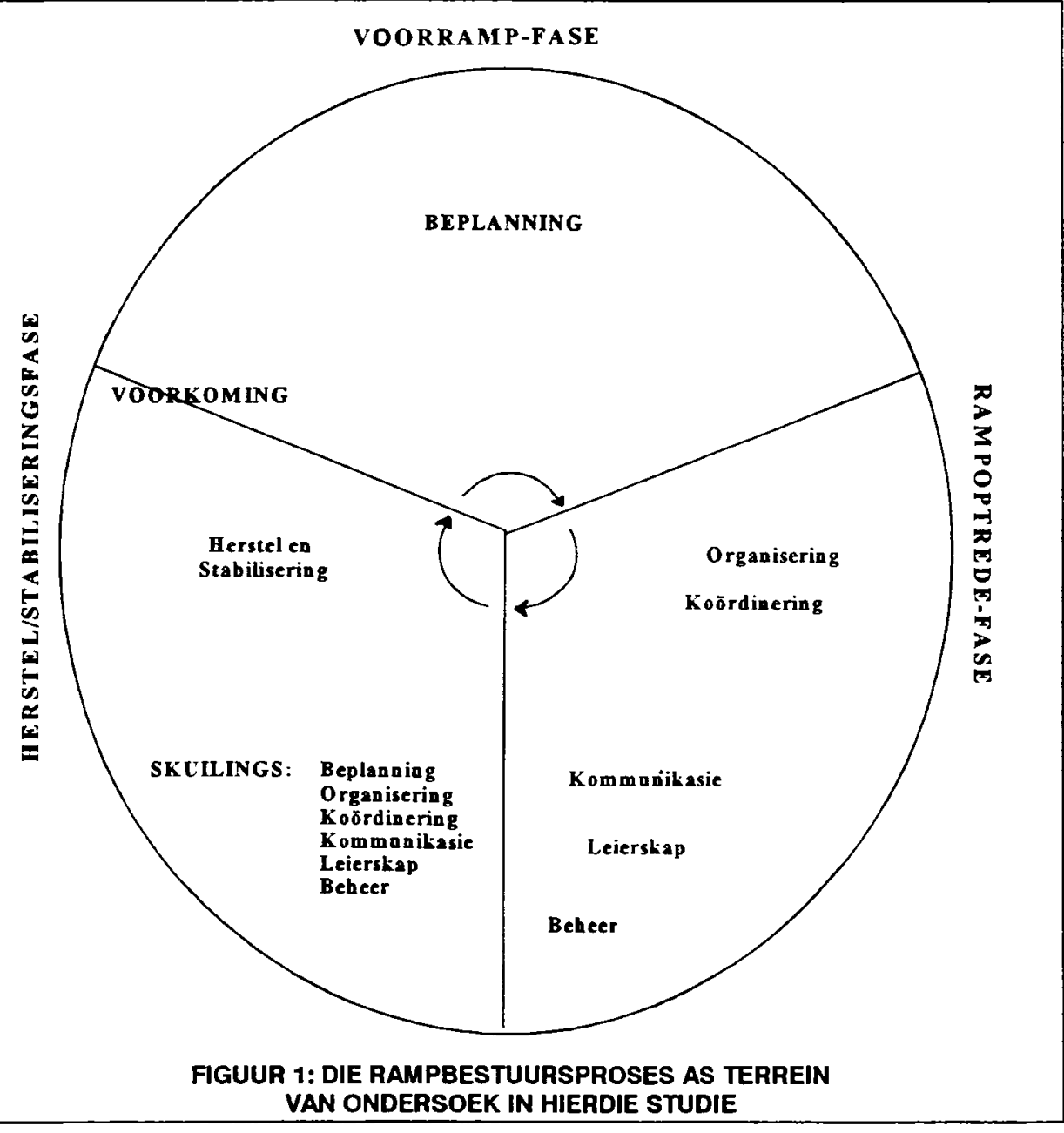

(60\%) het minder as 1 jaar ervaring gehad in die areas van ongevalle, ortopedie, intensiewesorg en buitepasiënte. Die meerderheid respondente, naamlik $88 \%$ het verpleegbestuurservaring gehad op dié van die posvlak van professionele verpleegkundige. Van die 96 respondente, was daar $23 \%$ wat nie voltyds gewerk het nie, $21 \%$ wat in staatsgesondheidsdienste werksaam was, $30 \%$ wat in die privaatsektor werksaam was en $25 \%$ wat by die plaaslike owerheid in diens was.

\section{IDENTIFISERING VAN BESTUURS. TAKE IN DIE VOORRAMPFASE}

\section{Beplanning}

Bestuurstake wat in die voorrampfase uitgevoer word, is as beplanningstake gelys. Daar was agt beplanningstake, naamlik doelwitbepaling (byvoorbeeld die toewysing van hulpbronne aan slagoffers met die beste kans op herstel) (item 1); die opstel van taakomskrywings vir al die verskillende poste van die lede van die mediese span (item 2); die prioriteitsbepaling van take, byvoorbeeld die beginsel dat lopende beseerdes eers behandel word, nadat ernstige beseerdes gestabiliseer is (item 3); die opstel van standaarde vir veilige sorg aan slagoffers, byvoorbeeld die hergebruik van voorraad, soos komberse (item 4); die opstel van standaarde vir die hantering van chemies-besoedelde klere van slagoffers (item 5); die bevordering van selfsorg deur die aanbied van noodhulpkursusse (item 6); motivering van lede van Burgerlike Beskerming om by rampoefeninge betrokke te wees (item 7) en die bepaling van risiko-elemente in die gemeenskap wat ' $n$ invloed op rampoptredes kan hê (item 8).

Daar was drie take waarop $75 \%$ van die respondente, en meer aangedui het dat die taak uitsluitlik dié van die rampverpleegster is:

* 'n Totaal van $79 \%$ respondente het aangedui dat prioriteitsbepaling van take 'n toepaslike bestuurstaak is. Hoewel dit nie moontlik is om die verloop van " $n$ ramp vooraf korrek te voorspel nie, is dit tóg belangrik om reeds in die beplanningsfase te onderskei tussen prioriteitstake en take wat van minder belang is. Dit voorkom verwarring, tydverkwisting en verkeerde benutting van beskikbare personeel op die ramptoneel (Garcia \& Lindsay 1985:269).

* 'n Totaal van $84 \%$ respondente het aangedui dat die opstel van standaarde vir veilige sorg aan slagoffers 'n taak van die rampverpleegster is. Hulle het dus aangetoon dat die rampverpleegster dié lid van die mediese span is wat moet beplan dat die omgewing en die gebruik van toerusting en voorrade tydens rampe nie mediese risiko's vir die slagoffers inhou nie.

* Daar is verder deur respondente aangetoon dat dit hoofsaaklik die plig van die rampverpleegster behoort te wees om lede van Burgerlike Beskerming te motiveer om by rampoefeninge betrokke te wees. 


\section{BESTUURSTAKE IN DIE RAMPOPTREDEFASE}

Bestuurstake wat tydens die rampoptrede-fase uitgevoer word, is as organiserings-, koördinerings-, kommunikasie-, leierskaps- en beheertake gelys. Daar was vier (4) organi-seringstake, vyf (5) koördineringstake, vier (4) kommunikasietake, ses (6) leierskapstake en drie (3) beheertake. Uit die totale aan (22) bestuurstake tydens die rampoptrede - fase, het $75 \%$ of meer van die respondente 12 take gëidentifiseer as die uitsluitlike verantwoordelikheid van die rampverpleegkundige.

* Betreffende die organiseringstake het dit na vore gekom dat die indeling van rampverpleegsters en noodhelpers in spanne om in die prioriteitsbehandelingsareas te werk, deur die respondente gesien is as deel van die besluitnemings- en organiseringsfunksies tydens ramphantering. Dit is belangrik dat spanne saamgestel word met inagneming van gesagslyne volgens die opleiding, ervaring en bestek van praktyk van elke vrywilliger, aldus Walsh (1989b:72); Mahoney (1970:66) en Skeet (1977:23).

* 'n Tweede taak wat hier na vore gekom het, was die toewysing van take aan die groot getalle vrywilligers wat gewoonlik tydens rampoptredes hulp aanbied en wat dan in spanne ingedeel en doelmatig aangewend moet word (Auf der Heide 1989: Hanna 1991:128).

* Betreffende die koördineringstake is drie take deur $75 \%$ of meer respondente as uitsluitlik dié van die rampverpleegster geïdentifiseer.

- Koördinering van die verskillende dissiplines in die mediese span sodat onderlinge konflik, naywer en kompetisie en die duplisering of nalaat van take nie voorkom nie, soos deur Auf der Heide (1989:174) aangedui, is as " $n$ belangrike bestuurstaak beskou.

- Die delegering van take aan opgeleide noodhelpers is ook deur die meerderheid respondente as 'n funksie van die rampverpleegster geïdentifiseer.

- Die meerderheid van die respondente, - naamlik $76 \%$ het gemeen dat dit die taak van die rampverpleegster is om toerusting en voorrade uit te reik, sodat opgeleide noodhelpers van voorraad en apparaat voorsien kan word om noodbehandeling toe te pas.

* Hoewel 'n gebrek aan kommunikasie beskou word as die hoofoorsaak van probleme wat vó́r, tydens of ná rampe ontstaan, is geen van die vier take wat onder hierdie opskrif gelys is, deur die respondente geidentifiseer as die spesifieke verantwoordelikheid van rampverpleegsters nie. As rede hiervoor is aangetoon dat rampverpleegsters moontlik nie die besondere belangrikheid van kommunikasie op die ramptoneel besef nie, of dat hulle bloot onkundig is betreffende die gebruik van kommunikasiemedia op die ramptoneel, of dat hulle die taak van kommunikasie as dié van die kommunikasiespan, wat deel uitmaak van die Burgerlike Beskermingspanne, gesien het.

Die kommunikasietake het ingesluit die oordra van noodsaaklike veiligheidsinligting aan spanlede, hantering van tweerigtingradio's, oordra van inligting aan hospitale en handhawing van oop kommunikasiekanale tussen spanne.

* Van die ses gelyste leierskapstake is vier (4) deur $75 \%$ en meer respondente aangedui as uitsluitlik die taak van die rampverpleegster.

- Ondersteuning van spanlede wat stres tydens die rampoptrede ervaar, dui op die besef by respondente dat die leier op die ramptoneel spanningsimptome by persone betrokke by noodleniging behoort te kan identifiseer, asook dienooreenkomstige stappe te neem om ondersteuning te verleen (Bruwer 1986:33; Errington 1989:91)

- Die belang van uitreiking van bevele op 'n wyse waarop die vrywillige samewerking van spanlede verkry sal word, byvoorbeeld die gebruik van oortuigingsmag, liewer as dwangmag, word ook deur verskeie outeurs soos Steadman (1988:225), Handmer \& Parker (1991:308) en Keenan (1991:548) bevestig.

- Rampverpleegsters besef die belang van 'n spanbenadering, aangesien die bevordering van " $n$ spangees, waar elke spanlid die ruimte geniet om volgens sy vermoëns sy taak te verrig, as ' $n$ belangrike taak van die rampverpleegster aangedui is.

- 'n Totaal van $87 \%$ van die respondente het aangedui dat die rampverpleegster haar bestuurstyl moet aanpas by die eise van die rampsituasie, byvoorbeeld dat sterk leiding geneem behoort te word wanneer onsekerheid by spanlede voorkom.

* Betreffende die drie beheerfunksies is al drie take deur $80 \%$ en meer respondente as noodsaaklik tydens rampoptredes uitgelig:

- Die bestuursverantwoordelikheid van die rampverpleegster betreffende die veiligheidsversekering van personeel is bevestig deur die sterk positiewe respons op die taak: "Die skep van 'n veilige omgewing vir almal betrokke by die rampoptrede, byvoorbeeld die uitreik van wegdoenbare handskoene."

- Die rampverpleegster het dit ook as haar plig beskou om toesig te hou oor mediese hulppersoneel om binne die toepaslike bestek van hulle praktyk op te tree.

- Die belang van behoorlike dokumentasie by die voortgesette behandeling van die rampslagoffer is besef deurdat die groot meerderheid respondente die kontrolering van skriftelike verslae betreffende die noodbehandeling van slagoffers as uitsluitlik die taak van die rampverpleegster aangedui het.

\section{BESTUURSTAKE IN DIE NÁRAMPFASE}

Die agt rampbestuurstake wat in die nárampfase geskied, is as volg in die instrument gelys:

* Bestuurstake van toepassing op die bestuur van skuilings

- Bepaling van die basiese behoeftes van die inwoners in tydelike skuilings.

- Improvisering van toerusting en voorrade.

- Berekening van noodrantsoene.

- Voorkoming van sekondêre rampe in tydelike skuilings.

\section{* Stabilisering van die gemeenskap}

- Verwysing vir krisisberaad.

- Inrig van fasiliteite om ligte beserings te behandel.

- Die tref van reëlings vir kritiese selfevaluering.

- Die tref van reëlings vir stresontlonting van almal betrokke by die rampoptrede.

Van hierdie agt take is vyf (5) deur $75 \%$ of meer respondente as die plig van die rampverpleegster geïdentifiseer:

Die bepaling van die basiese behoeftes van rampslagoffers in skuilings vir haweloses, byvoorbeeld die voorsiening van skoon water, was een van hierdie take. Volgens Steadman (1988:226) behoort die vaardighede van die rampverpleegster benut te word by die keuse, toerusting en personeelvoorsiening van skuilings, asook vir die psigiese en fisiese versorging van rampslagoffers. Die rampverpleegster behoort egter te poog om die alledaagse bestuur van skuilings aan ander geskikte persone op te dra.

- 'n Totaal van $75 \%$ respondente het aangedui dat die improvisering van toerusting, wanneer voorafbeplande voorraadstore uitgewis is, ' $n$ taak van die rampverpleegster is.

- Voorkoming van sekondêre rampe, deur byvoorbeeld die skep van afsonderingsfasiliteite vir aansteeklike siektes in skuilings en immunisering van slag-offers moet, volgens Lanros (1983:572), en die Wêreldgesondheidsorganisasie (WGO s.a.:17), voortdurend aandag geniet. Hierdie taak 
TABEL 1

Persentasie van response wat die vlakke van respondente se bestuursbevoegdheid aanduj:

$1=$ benodig opleiding

$2=$ benodig inoefening

$\mathbf{3}=$ benodig leiding $4=$ volkome bevoeg

\begin{tabular}{|c|c|c|c|c|c|}
\hline Item & Bestuurstake: Opleiding is nodig & 1 & 2 & 3 & 4 \\
\hline & & $\%$ & $\%$ & $\%$ & $\%$ \\
\hline $\mathrm{B} 2$ & Taakomskrnwing & 44 & 19 & 27 & 10 \\
\hline $\mathrm{B5}$ & Standaarde: chemiese gevare & 45 & 20 & 25 & 10 \\
\hline B6 & Bevordering van selfsorg/noodhulp & 45 & 22 & 18 & 15 \\
\hline $\mathrm{B} 13$ & Voorkoming: taakoorvleueling & 38 & 23 & 27 & 12 \\
\hline B18 & Kommunikasie: waarshuwings & 33 & 28 & 18 & 21 \\
\hline $\mathrm{B} 19$ & Hantering van kommunikasiemedia & 56 & 19 & 17 & 8 \\
\hline B33 & Berekening van noodrantsoene & 32 & 25 & 32 & 11 \\
\hline Item & Bestuurstake: Inoefening is nodig & 1 & 2 & 3 & 4 \\
\hline B7 & Motivering van lede & 19 & 31 & 27 & 23 \\
\hline $\mathrm{B} 17$ & Verspreiding van noodtoerusting & 19 & 33 & 24 & 24 \\
\hline Item & Bestuurstaak: Leiding is nodig & 1 & 2 & 3 & 4 \\
\hline $\mathrm{Bl}$ & Doelwitbepalmg & 35 & 25 & 36 & 4 \\
\hline B3 & Prioriteitsbepaling: take & 21 & 19 & 34 & 26 \\
\hline B4 & Standardisering vir veilige sorg & 16 & 18 & 35 & 31 \\
\hline B8 & Bepaling van risiko-elemente & 25 & 23 & 37 & 15 \\
\hline B9 & Sortering van beseerdes & 30 & 23 & 32 & 15 \\
\hline $\mathrm{B} 10$ & Besluitneming: afvoer & 19 & 23 & 38 & 20 \\
\hline B11 & Indeling van spanlede & 23 & 19 & 35 & 23 \\
\hline B 14 & Samewerking bewerkstellig & 26 & 21 & 35 & 18 \\
\hline $\mathrm{B} 16$ & Ontplooiing: ontvangsarea & 21 & 26 & 37 & 16 \\
\hline $\mathrm{B} 20$ & Kommunikasie met hospitale & 24 & 25 & 29 & 22 \\
\hline B21 & Kommunikasie tussen spanne & 27 & 28 & 32 & 13 \\
\hline $\mathrm{B} 22$ & Identifisering van wrywing & 18 & 22 & 32 & 28 \\
\hline $\mathrm{B} 23$ & Hantering van konflik & 21 & $1^{7}$ & 37 & 25 \\
\hline B24 & Ondersteuning van spanlede & 19 & 13 & 37 & 31 \\
\hline $\mathrm{B} 25$ & Uitreiking van bevele & 23 & 15 & 32 & 30 \\
\hline B31 & Bepaling van basiese behoeftes & 20 & 27 & 32 & 21 \\
\hline B34 & Voorkoming van sekondêre rampe & 23 & 22 & 36 & 19 \\
\hline B36 & Inrig van fasiliteite van beseerdes & 22 & 20 & 32 & 26 \\
\hline B37 & Reël vir selfevaluering & 32 & 21 & 36 & 11 \\
\hline B38 & Reël vir stresontlonting & 32 & 22 & 36 & 10 \\
\hline Item & Bestuurstaak: Volkome bevoeg & 1 & 2 & 3 & 4 \\
\hline $\mathrm{B} 12$ & Taaktoewysings aan vrywilligers & 14 & 15 & 34 & 37 \\
\hline $\mathrm{B} 15$ & Delegering van take aan noodhelpers & 18 & 17 & 19 & 46 \\
\hline $\mathrm{B} 26$ & Bevordering van spangees & 17 & 12 & 29 & 42 \\
\hline $\mathrm{B} 27$ & Aanpassing van bestuursstyl & 21 & 17 & 27 & 35 \\
\hline $\mathrm{B} 28$ & Beveiliging van personeel & 14 & 18 & 26 & 42 \\
\hline B29 & Toesighouding: hulppersoneel & 21 & 13 & 32 & 34 \\
\hline $\mathrm{B} 30$ & Kontrolering van verslae & 18 & 15 & 23 & 44 \\
\hline $\mathrm{B} 32$ & Improvisering van toerusting & 24 & 25 & 24 & 27 \\
\hline B35 & Veruysing vir krisisberaad & 17 & 16 & 32 & 35 \\
\hline
\end{tabular}


is dan ook as dié van die rampverpleegster gesien.

- Die respondente het aangedui dat die verwysing van persone in rou, vir krisisberaad, ' $n$ taak van die rampverpleegster behoort te wees.

- Volgens $82 \%$ van die respondente is die rampverpleegster die aangewese persoon om die verantwoordelikheid te neem vir die inrig van noodsorgfasiliteite om vir die behandeling van ligte beserings voorsiening te maak.

\section{BESTUURSTAKE GEÏDENTIFISEER AS UTTSLUTTLIK DIÉ VAN DIE RAMPVER-PLEEGSTER}

Ter samevatting is die 20 rampbestuurstake wat deur die respondente geidentifiseer is as bestuurstake wat uitsluitlik deur die rampverpleegster uitgevoer moet word, as volg:

\section{* Tydens die voorrampfase}

- Opstel van standaarde vir veilige sorg aan slagoffers.

- Prioriteitsbepaling van take op die ramptoneel.

- Motivering van lede van Burgerlike Beskerming om betrokke te wees.

\section{* Tydens die rampoptredefase}

- Skep van 'n veilige omgewing vir personeel en helpers.

- Bevordering van ' $n$ spangees.

- Die uitreik van bevele op ' $n$ wyse wat vrywillige samewerking verseker.

- Kontrolering van skriftelike verslae.

- Aanpassing van die bestuurstyl by die eise van die rampoptrede.

- Toesighouding oor mediese hulppersoneel betreffende bestek van praktyk.

- Delegering van take aan opgeleide noodhelpers.

- Ondersteuning van spanlede wat stres ervaar.

- Spanindeling van rampverpleegsters en noodhelpers.

- Toewysing van take aan vrywilligers.

- Verspreiding van noodtoerusting aan spanlede in noodbehandelingsareas.

- Bewerkstelliging van samewerking ‘tussen die verskillende dissiplines.

\section{* Tydens die nárampfase}

- Voorkoming van sekondêre rampe.

- Inrig van fasiliteite om groot getalle ligte beserings te behandel.

- Verwysing van persone in rou vir krisisberaad.

- Bepaling van die basiese behoeftes van rampslagoffers in skuilings.

- Improvisering van toerusting.

Dit blyk dus uit hierdie studie dat die respondente verwag het dat die rampverpleegster meer as die helfte van die bestuurstake, soos dit in die vraelys voorgekom het, beslis sou verrig het indien sy by die rampbestuursproses betrokke sou wees.

\section{MENINGS BETREFFENDE BEVOEGDHEID OM DIE GEÏDENTIFLSEERDE BESTUURSTAKE UIT TE VOER}

Respondente is gevra om benewens die belang van ' $n$ bestuurstaak vir rampverpleegsteroptrede, ook aan te dui hoe bevoeg hulle hulself geag het om elke gelyste bestuurstaak te kan uitvoer. Teenoor elke taak moes hulle 'n keuse aandui betreffende die volgende: "volkome bevoeg", "het leiding nodig", "het inoefening nodig" of "het opleiding nodig".

Die menings van die respondente word in Tabel 1 weergegee.

\section{AANBEVELINGS}

Van die belangrikste aanbevelings wat gemaak is, was die volgende:

* Alle rampverpleegsters behoort noodhulpopleiding te ondergaan tot ten minste die derde vlak, maar verkieslik tot die vlak van die basiese ambulanskursus.

* ' $\mathrm{n}$ Spesifieke noodhulpkursus vir rampverpleegsters behoort bykomend tot die bestaande noodhulpopleiding aangebied te word.

* Volledige taakbeskrywings moet vir die rampverpleegster as lid van die mediese span opgestel word, wat haar bestuursrol en verhouding tot ander spanlede van ander dissiplines omskryf.

* ' $n$ Kursus in rampbestuur vir verpleegsters behoort ontwerp te word.

\section{VOORGESTELDE INHOUD VAN KURSUS IN RAMPBESTUUR}

* Voorvereiste module: noodhulp vir rampverpleegsters

- Derde vlak - sertifikaat in noodhulp.

- Gevorderde verpleegtegnieke.

- Beginsels van die hantering van massaslagoffers.

- Noodhulpvaardighede in spesifieke rampsituasies (League of Red Cross and Red Crescent Societies 1985:43).

\section{* Module een: chemiese ongevalle}

- Gevare in die chemiese industrie en spesifieke gebiede.

- Aard van chemiese besoedeling.

- Voorkoming van chemiese besoedeling.

- Lang- en korttermyn gevolge van besoedeling.

- Beplanning vir moontlike chemiese besoedeling.
- Hantering van chemies-besoedelde voorwerpe (Baxter 1991: 61; Bomberger 1985:176; Sidell 1990:70).

* Module twee: rampbeplanning

- Doelwitbepaling in rampbestuur.

- Take van verskillende dissiplines en taakomskrywings.

- Prioriteitsbepaling van take.

- Standaarde vir veilige sorg aan slagoffers.

- Risiko-elemente in die gemeenskap.

- Bevordering van selfsorg in die gemeenskap.

- Motivering van vrywilligers.

- Mobilisering van hulpbronne.

- Waarskuwings.

- Ontruiming van gemeenskappe.

* Module drie: organisering en koördinering op die ramptoneel

- Ontplooiing van ' $n$ noodsorgpos.

- Sortering (triage) van beseerdes.

- Spanbou en samewerking.

- Besluitneming tydens krisissituasies.

- Hantering van vrywilligers.

- Delegering van take.

- Hantering van noodtoerusting en -voorrade.

* Module vier: kommunikasie tydens die rampbestuursproses

- Faktore wat kommunikasie tydens rampe beïnvloed.

- Handhawing van oop kommunikasiekanale tussen almal op die ramptoneel.

- Kommunikasie tussen spanne en beheerinstellings.

- Kommunikasie met hospitale.

- Hantering van kommunikasiemedia tydens rampe (Auf der Heide 1989:80).

\section{* Module vyf: bestuur van skuilings}

- Basiese behoeftes van haweloses in skuilings.

- Noodvoorrade vir skuilings.

- Personeelvoorsiening in skuilings.

- Improvisering van toerusting.

- Fasiliteite vir die behandeling van groot getalle ligte beserings.

- Voorkoming van sekondêre rampe in skuilings en in die gemeenskap.

- Psigologiese reaksies na rampe.

- Verwysing van persone vir krisisberaad.

- Kritiese selfevaluering deur alle spanlede.

- Stresontlonting na rampoptredes (Mickelson 1985:203; Richtsmeier \& Miller 1985:187); Steadman 1988:218).

* Module ses: verpleegleierskap in rampsituasies

Oorsake van wrywing tussen spanlede.

- Konflikhantering.

- Ondersteuningstelsels vir spanlede wat stres ervaar. 
- Samewerking en die uitreik van bevele.

- Bevordering van 'n spangees.

- Bestuurstyle tydens rampoptredes.

* Module sewe: beheerfunksies tydens rampe

- Die veiligheid van noodhelpers.

- Toesighouding oor mediese hulppersoneel en vrywilligers.

- Kontrolering van skriftelike verslae.

- Wetlike en etiese aspekte van rampbestuur.

- Evaluering van rampoptredes.

\section{SLOT}

Die noodsaaklike bestuursrol van die rampverpleegster vóór, tydens asook ná rampe is ondersoek. Die bevoegdheid van die rampverpleegster om die verskillende rampbestuurstake te verrig, is ook nagegaan. Dit het geblyk dat opleiding in die meeste take nodig is, en ' $n$ kursus in rampbestuur is vir verpleegkundiges ontwerp.

\section{VERWYSINGS}

Auf der Heide, E. (1989). Disaster response: Principals of Preparation and Coordination. St. Louis: Mosby.

Baxter, PJ. (1991). Major chemical disasters Britain's health services are poorly prepared. British Medical Joumal, vol. 302(6768):61-62.

Bomberger. AS. (1985). Management of the irradiated patient. In Disaster Nursing planning, assessment and intervention, Garcia, LM (ed.) Rockville: Aspen.
Bruwer, A. (1986). Psigologiese reaksies en aspekte van ramptoestande. Nursing RSA Verpleging, vol $1(4) 32-33,35$.

Wet op Burgerlike Beskerming, no. 67 van (1977).

Errington, G. (1989). Stress among disaster nurses and relief workers. International Nursing Review, vol 36(3)90-92.

Handmer, J \& Parker, D. (1991). British Disaster Planning and Management: An initial assessment.Disasters, vol.15(4):303-317.

Hanna, JA. (1991). Disaster planning for health care facilities. Ottowa:Canadian Hospital Press.

Keenan, J. (1991). Disaster management - an exercise in logistics. Trauma and Emergency Medicine, vol. 8(2):547-551.

Lanros, NE. (1983). Assessment and intervention in emergency nursing. 2nd edition. Maryland: Prentice-Hall.

League of Red Cross and Red Crescent Societies (1985). Guidelines for Nurses in Disaster Preparedness and Relief Published by the WHO in collaboration with the League of Red Cross and Red Crescent Societies. WHO-Geneva.

Mahoney, RF. (1970). Emergency and disaster nursing. Tweede uitgawe. London: MacMillan Co.

Mickelson, RD. (1985). Establishing and managing a shelter, in Disaster nursing planning and intervention, Garcia, LM. Rockville:Aspen.

Richtsmeier, JL \& Miller, JR. (1985). Psychological aspects of disaster situations, in Disaster nursing planning, assessment and intervention, Garcia, LM. Rockville:Aspen.

Sidell, FR. (1990). What to do in case of an inthinkable chemical warfare. Postgraduate Medicine, vol. 88(7)70-76, 81-84,101-102.
Skeet, M. (1977). Manual for disaster relief work. Edinburgh:Churchill Livingstone.

Steadman, RE. (1988). Nursing aspects of disaster management, in Medicine for disasters, First edition. Baskett, P \& Weller, R. (ed.) London:Wright.

Walsh, M. (1989). Disasters, current planning and recent experience. London: Edward Amold.

WGO [s.a.]. Health for all when a disaster strikes. Health emergency preparedness and response in African countries, vol. 3 Addis Ababa:Panafrican Centre for Emergency preparedness and response. WHO.

sUSAN BOOYENS
D.LITT et PHIL, Geregistreerde algemene
verpleegkundige, vroedvrou, dosent,
verpleegbestuurder, gemeenskap-en
intensiewesorg verpleegkundige.
PROFESSOR, DEPARTEMENT
VERPLEEGKUNDE,
UNIVERSITEIT VAN SUID-AFRIKA
(UNISA)
EN
ANNALET PEROLD
M.A. CUR, Geregistreerde algemene
verpleegkundige, vroedvrou, dosent,
verpleegbestuUrder en
gemeenskapverpleegkundige.
LEKTRISE, DEPARTEMENT
VERPLEEGKUNDE,
UNIVERSITEIT VAN SUID-AFRIKA
(UNISA)

